\title{
Environmental Thermal Performance of Prefabricated Buildings Based on Building Wall Energy-Saving Technology
}

\author{
Dezhi Zou ${ }^{1,2 *}$, Cheng Sun ${ }^{1}$ \\ ${ }^{1}$ School of Architecture, Harbin Institute of Technology, Key Laboratory of Cold Region Urban and Rural Human Settlement \\ Environment Science and Technology, Ministry of Industry and Information Technology, Harbin 150001, China \\ ${ }^{2}$ Architecture College, Inner Mongolia University of Technology, Inner Mongolia Key Laboratory of Green Building, Huhhot \\ 010051 , China
}

Corresponding Author Email: zdz@imut.edu.cn

https://doi.org/10.18280/ijsdp.150621

Received: 1 April 2020

Accepted: 10 July 2020

\section{Keywords:}

prefabricated building, building walls, energy-saving, composite insulation block, environmental thermal performance

\begin{abstract}
In prefabricated buildings, the building walls act as thermal insulation layers of the building envelope. The walls in the envelope consume $50 \%$ of the energy consumed by the whole building. To promote prefabricated buildings, it is very important to design energy-saving exterior walls. Focusing on prefabricated building in Inner Mongolia, this paper designs a novel composite thermal insulation block for building walls based on coal gangue ceramsites and polyethylene insulation boards, and probes deep into its mechanical properties and environmental thermal performance. The results show that, with the growing content of coal gangue ceramsites, the composite thermal insulation block saw a linear decline in volume density, compressive strength, and thermal conductivity; the theoretical heat transfer coefficient of the proposed insulation block deviated slightly from the calculated value, indicating the feasibility of the calculated heat transfer coefficient. The research results promote the application of new building walls in the design of prefabricated buildings.
\end{abstract}

\section{INTRODUCTION}

China is a big energy consumer, and energy consumption is increasing gradually. The energy consumed by buildings accounts for over $1 / 3$ of the world's total energy consumption [1]. It is important to adopt energy-saving technologies in buildings. In northern China, there is a long heating period every year. To reduce the coal consumption in heating supply, the insulation and energy-saving effects of building wall materials must be improved [2].

There are many types of energy-saving building walls, including exterior insulation, sandwich insulation, and composite insulation. The exterior insulation and composite insulation are usually employed in prefabricated buildings, which is a new trend in architectural engineering. The walls of prefabricated buildings mostly use light, low-density, thermal insulation materials [3-5].

For exterior insulation, the common insulation materials are polystyrene board and rock wool. The polystyrene board has a poor fire resistance, while rock wool is too costly to fabricate. As a result, more prefabricated buildings adopt composite insulation in its walls than exterior insulation [6]. The most intuitive response of the envelope is the temperature fluctuation on the inner surface of the envelope and the indoor temperature fluctuation [7]. The core of the energy-saving design of the building is to solve the heat loss of the thermal bridge in winter, maintain the thermal stability of the interior, and maintain the high temperature of the inner surface after being subjected to the periodic thermal action of internal and external.

Some scholars filled polystyrene boards into the masonry formwork, creating a sandwich insulation. The sandwich insulation successfully reduces the existence of cold bridges, and its thermal conductivity suppresses the heat transfer coefficient of building walls [8]. The application of selfinsulation material also greatly reduces the thermal loss of the walls. Both sandwich insulation and self-insulation material could significantly enhance the insulation performance of building walls [9].

The addition of heat insulation always reduces the stability of the inner surface of the building envelope, regardless of the type of walls and the setting of insulation layers. In some highend commercial buildings, heat insulation and high-reflective coatings are applied directly to the fabricated exterior walls, reducing the heat transfer of the exterior walls by $90 \%[10,11]$.

Focusing on prefabricated buildings in Inner Mongolia, this paper designs a novel composite thermal insulation block for building walls, and probes deep into its mechanical properties and environmental thermal performance. The research results promote the application of new building walls in the design of prefabricated buildings.

\section{MATERIAL PROPERTIES AND TYPE SELECTION OF THE NEW-TYPE COMPOSITE THERMAL INSULATION BLOCKS}

\subsection{Material properties}

At present, the walls of prefabricated buildings are mostly masonry formworks, and a minor part of them are splicing prefabricated walls. This paper chooses to study the most 
commonly used masonry structure [12]. Under normal circumstances, the thicker the walls, the smaller the heat loss; however, in order not to increase the thickness of the wall or occupy the effective space of the house, it's necessary to consider from the aspects of energy saving, thermal insulation, service life, and costs, and combine with the actual materials available in the area of Inner Mongolia to prepare a new-type composite thermal insulation block for the building walls [1315]. As a coarse and fine aggregate, ceramsite has certain thermal insulation properties. There are many mines in Inner Mongolia, and the coal gangue produced by the mining industry has become the largest industrial solid waste in the region. The preparation of ceramsites with coal gangue not only makes use of a large amount of solid waste, but also greatly improves the material's heat storage and thermal insulation capabilities. Figure 1 is a picture of the coal gangue ceramsites. There are a lot of pores inside the structure of coal gangue ceramsites. The P.O. 42.5 ordinary cement produced by Inner Mongolia Xizhuozi Co. Ltd. was selected as the cement in the study; as for the coal gangue ceramsites, the particle size was $1 \mathrm{~mm}-5 \mathrm{~mm}$ continuous grading, and the particle size of the ordinary sandstone was the same as that of the coal gangue ceramsites, the content of the coal gangue ceramsites was $0 \%, 10 \%, 20 \%, 30 \%, 40 \%$ and $50 \%$, respectively. The insulation material was made of polyethylene foam boards with a thermal conductivity of $0.037 \mathrm{~W} / \mathrm{m}^{2} \cdot \mathrm{K}$ and a thickness of $50 \mathrm{~mm}$.

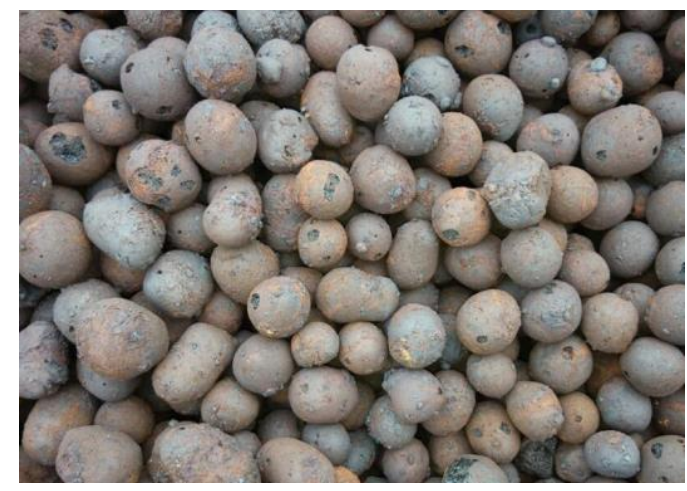

Figure 1. Pore structure of coal gangue ceramsites

\subsection{Type selection}

The heat insulation performance of the envelope is different with the different form of the envelope. The new-type composite thermal insulation blocks designed in this study consisted of three layers of concrete slabs and two layers of polyethylene foam boards. The standard size of the block was $390 \mathrm{~mm} \times 240 \mathrm{~mm} \times 190 \mathrm{~mm}$, as shown in Figure 2 . One groove column of the blocks was kept empty, and the overall stretchdraw was conducted with the help of the plastic tie bars, so as to enhance the integrity of the walls, and thereby reducing the cold bridge effect of the mortar joints. By combining the coal gangue ceramsite mortar base material with the polyethylene foam boards, and changing the content of coal gangue ceramsites, this study investigated the strength and thermal insulation performance of the composite thermal insulation blocks. Figure 3 shows the volume density of the blocks with different coal gangue ceramsite contents. It can be clearly seen that with the increase of the coal gangue ceramsite content, the volume density of the composite thermal insulation blocks decreased linearly. Compared with the composite thermal insulation blocks with a coal gangue ceramsite content of $0 \%$, when the coal gangue ceramsite content was $10 \%, 20 \%, 30 \%$, $40 \%$ and $50 \%$ respectively, the volume density of the composite thermal insulation blocks decreased by $2.45 \%$, $4.95 \%, 9.06 \%, 12.03 \%$ and $17.50 \%$, respectively.

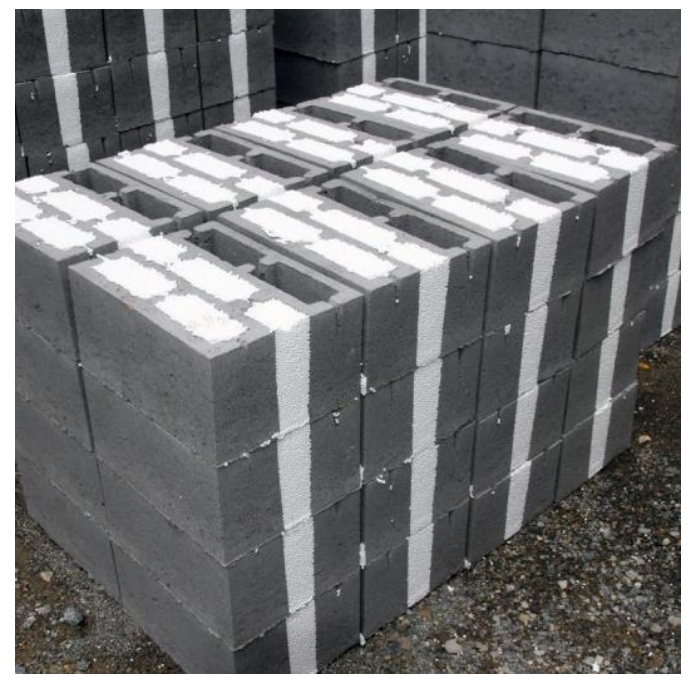

Figure 2. Structure of composite thermal insulation blocks

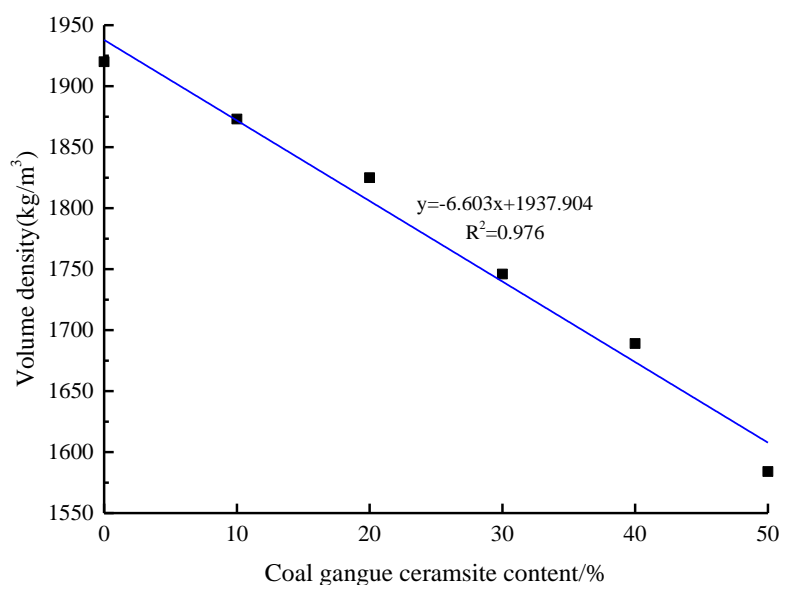

Figure 3. Volume density of thermal insulation blocks with different coal gangue ceramsite contents

\section{PROPERTIES OF THE NEW-TYPE COMPOSITE THERMAL INSULATION BLOCKS}

The porous structure of the coal gangue ceramsites reduces the propagation speed of the heat bridge, and it can achieve the effects of heat absorption during the day and thermal insulation during the night. Therefore, compared with ordinary prefabricated cement boards or other building blocks, composite thermal insulation blocks have better heat storage capacity [16-18]. To test the strength and thermal properties of the composite thermal insulation blocks, standard samples with a size of $390 \mathrm{~mm} \times 240 \mathrm{~mm} \times 190 \mathrm{~mm}$ had been prepared. The compressive strength test was carried out in accordance with the Standard for Test Method of Performance on Building Mortar (JGJ-2009), each test was performed on three test blocks. Thermal conductivity and softening coefficient are the most important parameters that affect the properties of the composite thermal insulation blocks, and the Transient Plane Source (TPS) method was adopted for the tests. The softening 
coefficient of the material is an important indicator to measure the water resistance of the material. In this study, the compressive strength of the composite thermal insulation blocks was tested after the blocks being saturated with water for $48 \mathrm{~h}$, and the ratio of the saturated compressive strength to the dried compressive strength was taken as the softening coefficient.

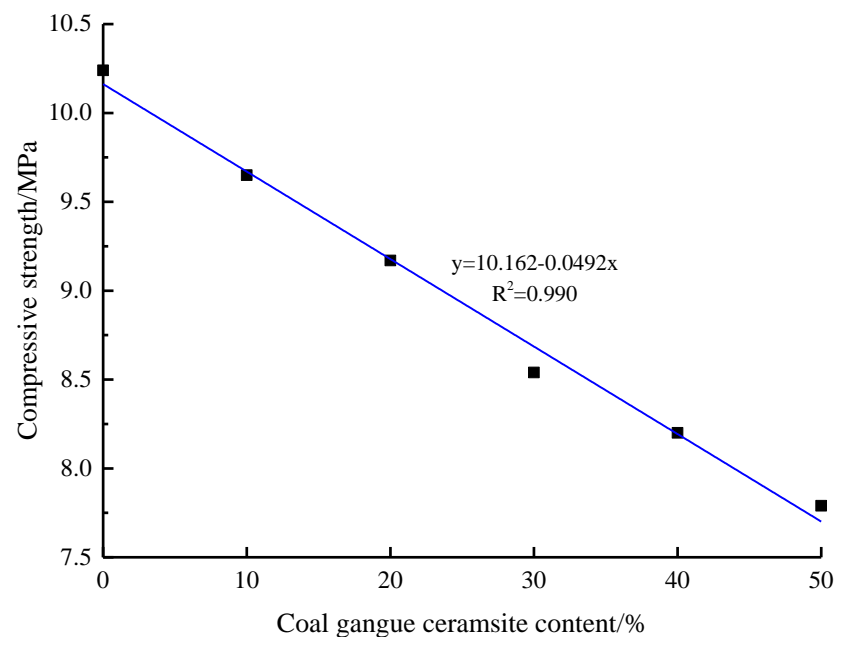

Figure 4. Compressive strength of thermal insulation blocks

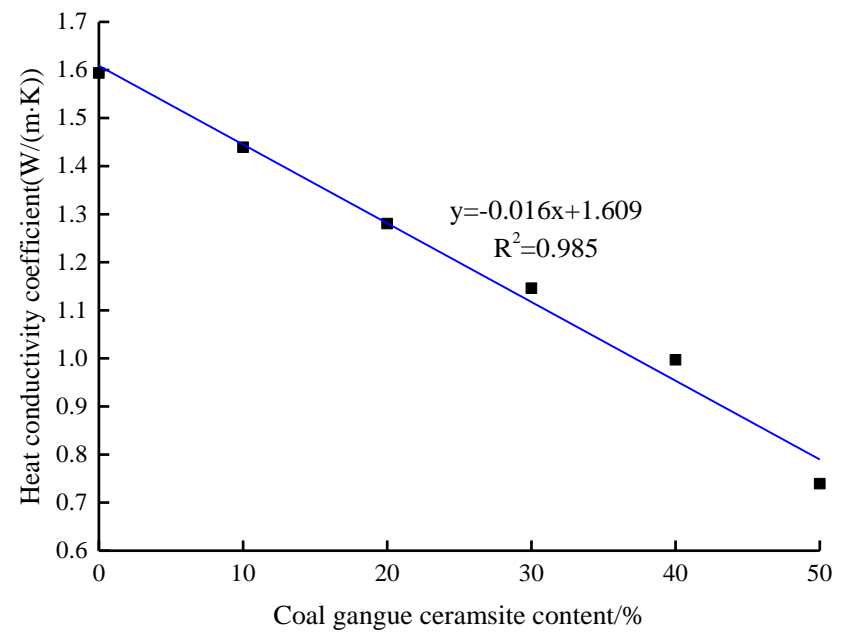

Figure 5. Thermal conductivity coefficient of the composite thermal insulation blocks

Figure 4 shows the compressive strength of the thermal insulation blocks. With the increase of the content of coal gangue ceramsites, the compressive strength of the thermal insulation blocks decreased. Compared with the compressive strength of the thermal insulation blocks with a coal gangue ceramsite content of $0 \%$, the compressive strength of the thermal insulation blocks with a coal gangue ceramsite content of $10 \%, 20 \%, 30 \%, 40 \%$, and $50 \%$ decreased by $5.76 \%$, $10.45 \%, 16.60 \%, 19.92 \%$ and $23.93 \%$, respectively. Figure 5 shows the thermal conductivity coefficient of the new-type composite thermal insulation blocks. It can be clearly seen that the value of the thermal conductivity coefficient of the composite thermal insulation blocks exhibited the same linear decline trend as the compressive strength, it's mainly because of the porous and light weight features of the coal gangue ceramsites, which resulted in a decrease in both the compressive strength and the thermal conductivity. Figure 6 shows the softening coefficient of the new-type composite thermal insulation blocks. It can be clearly seen that when the content of coal gangue ceramsites was $30 \%$, the composite thermal insulation blocks had the highest softening coefficient and the best water resistance performance.

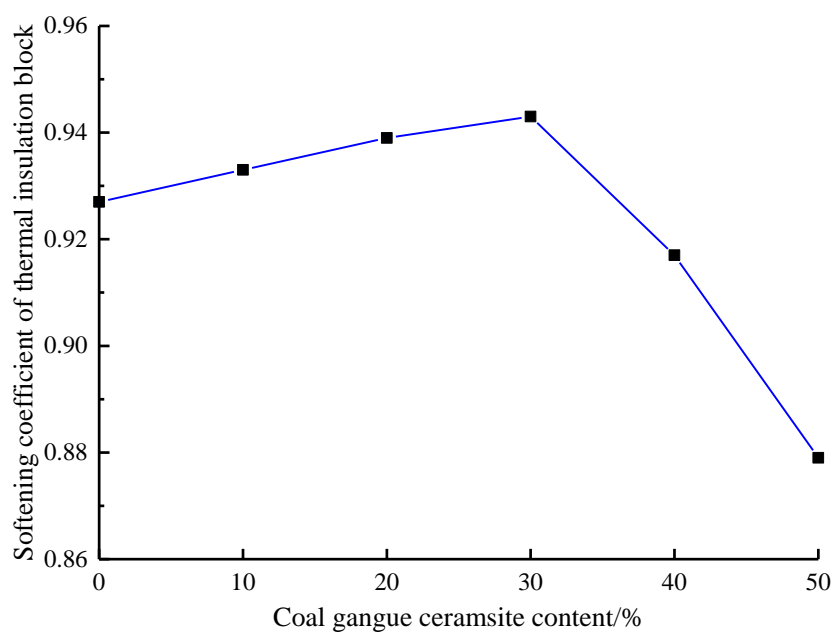

Figure 6. Softening coefficient of the composite thermal insulation blocks

\section{ENVIRONMENTAL THERMAL PROPERTIES OF PREFABRICATED BUILDING WALLS}

\subsection{Theoretical calculation of the environmental thermal properties of prefabricated building walls}

Inner Mongolia is located in areas where the winter is severe cold. The environmental thermal properties of building walls mainly refer to the heat preservation performance and the thermal insulation performance, the heat preservation performance is related to the heat transfer coefficient of the walls, and the thermal insulation performance is related to the thermal resistance of the walls [19-21]. According to the Code for Thermal Design of Civil Buildings and the different regions, the thermal resistance of the wall should be greater than the specified minimum value; the heat transfer coefficient is related to the structure of the building, and Table 1 gives the limits of the heat transfer coefficient in Inner Mongolia. Buildings in Inner Mongolia require good heating output to ensure a comfortable living environment inside the prefabricated buildings, so the limits of the heat transfer coefficient and thermal resistance of the exterior walls should be strictly satisfied. After test, the heat transfer coefficient of the composite thermal insulation blocks designed in this study was measured to be $0.326 \mathrm{~W} / \mathrm{m}^{2} \cdot \mathrm{K}$, which was lower than 0.45 $\mathrm{W} / \mathrm{m}^{2} \cdot \mathrm{K}$, the value required in Inner Mongolia area.

The composite thermal insulation block designed in this study was two-phase heterogeneous material, and its average thermal resistance $\bar{R}$ was calculated as shown in Formula 1 below:

$$
\bar{R}=\left[\frac{F_{0}}{\frac{F_{1}}{R_{1}}+\frac{F_{2}}{R_{2}}+\cdots+\frac{F_{n}}{R_{n}}}-\left(R_{i}+R_{e}\right)\right] \varphi
$$

where, $\mathrm{F}_{0}$ represents the total heat transfer area perpendicular to the heat flow direction, $\mathrm{m}^{2}$; 
$F_{1}, F_{2} \cdots F_{n}$ represent the area of each heat transfer surface parallel to the heat flow direction, $\mathrm{m}^{2}$;

$\mathrm{R}_{1}, \mathrm{R}_{2} \cdots \mathrm{R}_{\mathrm{n}}$ represent the heat transfer resistance of each heat transfer surface positions, $\mathrm{W} / \mathrm{m}^{2} \cdot \mathrm{K}$;

$\mathrm{R}_{\mathrm{i}}$ and $\mathrm{R}_{\mathrm{e}}$ represent the heat transfer resistance of the inner surface and the outer surface, respectively, the values are 0.11 and $0.04 \mathrm{~W} / \mathrm{m}^{2} \cdot \mathrm{K}$;

$\varphi$ represents the correction coefficient, and its value is in accordance with Table 2 .

The heat transfer resistance of the envelope structure can be calculated by Formula 2:

$$
\mathrm{R}_{0}=\mathrm{R}_{\mathrm{i}}+\mathrm{R}+\mathrm{R}_{\mathrm{e}}
$$

According to above results, this paper selected the composite thermal insulation blocks with a 50\% coal gangue ceramsite content for calculation. The thermal conductivity coefficient of the mortar was $0.7793 \mathrm{~W} / \mathrm{m}^{2} \cdot \mathrm{K}$, and the thermal conductivity of the thermal insulation material was $0.037 \mathrm{~W} / \mathrm{m}^{2} \cdot \mathrm{K}$. In order to reduce the impact on the thermal insulation boards during construction or pouring process, the thermal conductivity of the boards had been expanded by 1.2 times, which was $0.0444 \mathrm{~W} / \mathrm{m}^{2} \cdot \mathrm{K}$. The cross-section used the multi-layer materials to maintain the exterior walls, and the thermal resistance $\mathrm{R}$ was calculated as follows:

$$
\begin{gathered}
\mathrm{R}=\mathrm{R}_{1}+\mathrm{R}_{2}=0.09 / 0.7793+0.1 / 0.0444=2.368 \mathrm{~W} / \mathrm{m}^{2} \cdot \mathrm{K} \\
\mathrm{R}_{0}=\mathrm{R}_{\mathrm{i}}+\mathrm{R}+\mathrm{R}_{\mathrm{e}}=0.11+2.368+0.04=2.518 \mathrm{~W} / \mathrm{m}^{2} \cdot \mathrm{K}
\end{gathered}
$$

That is:

$$
\text { heat transfer coefficient }=1 / \mathrm{R}_{0}=0.397 \mathrm{~W} / \mathrm{m}^{2} \cdot \mathrm{K}
$$

Table 1. Limits of heat transfer coefficient in Inner Mongolia

\begin{tabular}{ccc}
\hline \multirow{2}{*}{ Enclosure part } & \multicolumn{2}{c}{ Heat transfer coefficient $\left(\mathrm{W} / \mathrm{m}^{2} \cdot \mathrm{K}\right)$} \\
\cline { 2 - 3 } & $\mathrm{S} \leq 0.3$ & $0.3<\mathrm{S} \leq 0.4$ \\
\hline Exterior wall & 0.5 & 0.45 \\
\hline
\end{tabular}

Table 2. Correction factor value

\begin{tabular}{cc}
\hline$\gamma_{2} / r_{1}$ and $\left(\gamma_{2}+\gamma_{3}\right) / 2 \gamma_{1}$ & $\varphi$ \\
\hline $0.09-0.10$ & 0.86 \\
$0.20-0.39$ & 0.93 \\
$0.40-0.69$ & 0.96 \\
$0.70-0.99$ & 0.98 \\
\hline
\end{tabular}

\subsection{Test results of the environmental thermal properties of prefabricated building walls}

In this paper, the thermal properties of the new-type composite thermal insulation blocks were obtained through calculation, which provided great help for its application in prefabricated building walls. The boundary conditions of the composite thermal insulation blocks containing coal gangue ceramsites were quite complex, so it's difficult to conduct real tests based on the actual temperature field. This paper used the Ansys finite element simulation software to analyze the composite thermal insulation blocks containing coal gangue ceramsites, and concluded the changes of temperature field, temperature gradient and heat flow density under stable heat transfer conditions. The heat transfer coefficient of the thermal insulation blocks analyzed by Ansys was $0.469 \mathrm{~W} / \mathrm{m}^{2} \cdot \mathrm{K}$, and the calculated heat transfer coefficient was $0.397 \mathrm{~W} / \mathrm{m}^{2} \cdot \mathrm{K}$, the error between the theoretical value and the calculated value was $15.35 \%$, less than $20 \%$, so it can be considered that the calculated heat transfer coefficient is feasible.

\section{CONCLUSIONS}

This paper took prefabricated buildings in Inner Mongolia as the research objects, it designed a new-type composite thermal insulation blocks for the building walls, and probed deep into its mechanical properties and environmental thermal properties. The specific conclusions are as follows:

(1) With the increase of the content of coal gangue ceramsites, the volume density, compressive strength and thermal conductivity of the composite thermal insulation blocks all decreased linearly, this was mainly related to the porous structure and the heat storage performance of the coal gangue ceramsites.

(2) The porous structure of coal gangue ceramsites reduced the propagation speed of the heat bridge, which can achieve the effects of heat absorption during the day and heat preservation during the night. When the content of coal gangue ceramsites was $30 \%$, the softening coefficient of the composite thermal insulation blocks reached the highest, and the water resistance performance was the best.

(3) Inner Mongolia is a region with severe cold winter, so the heat transfer coefficient and thermal resistance of the exterior walls should be strictly restricted. The heat transfer coefficient of the thermal insulation blocks analyzed by Ansys was $0.469 \mathrm{~W} / \mathrm{m}^{2} \cdot \mathrm{K}$, and the calculated heat transfer coefficient was $0.397 \mathrm{~W} / \mathrm{m}^{2} \cdot \mathrm{K}$. Compared with concrete walls, the composite thermal insulation blocks have a smaller heat transfer coefficient, and they have excellent heat preservation and thermal insulation capacities.

\section{ACKNOWLEDGEMENTS}

This work was supported by the Natural Science Foundation of Inner Mongolia University of Technology (IMUT) (Grant No.: X201711) and the Inner Mongolia Natural Science Foundation (Grant No.: 2018MS05049).

\section{REFERENCES}

[1] Han, Z.G., Song, X.F., Hao, R.Q. (2011). The assembled structure analysis of energy conservation and material saving unit sheet aluminum curtain wall. In Advanced Materials Research, 243: 6165-6168. https://doi.org/10.4028/www.scientific.net/AMR.243249.6165

[2] Adekunle, T.O., Nikolopoulou, M. (2019). Winter performance, occupants' comfort and cold stress in prefabricated timber buildings. Building and Environment, 149 : 220-240. https://doi.org/10.1016/j.buildenv.2018.12.019

[3] Mutani, G., Azzolino, C., Macrì, M., Mancuso, S. (2020). Straw buildings: A good compromise between environmental sustainability and energy-economic savings. Applied Sciences, 10(8): 2858. https://doi.org/10.3390/app10082858

[4] Delgado, M.G., Ramos, J.S., Domínguez, S.Á., Ríos, 
J.A.T., Cabeza, L.F. (2020). Building thermal storage technology: Compensating renewable energy fluctuations. Journal of Energy Storage, 27: 101147. https://doi.org/10.1016/j.est.2019.101147

[5] Levinson, R., Akbari, H. (2010). Potential benefits of cool roofs on commercial buildings: conserving energy, saving money, and reducing emission of greenhouse gases and air pollutants. Energy Efficiency, 3(1): 53. https://doi.org/10.1007/s12053-008-9038-2

[6] Huo, H., Shao, J., Huo, H. (2017). Contributions of energy-saving technologies to building energy saving in different climatic regions of China. Applied Thermal Engineering, 124: 1159-1168. https://doi.org/10.1016/j.applthermaleng.2017.06.065

[7] Sudan, M., Tiwari, G.N., Al-Helal, I.M. (2015). Dynamic analysis of daylight metrics and energy saving for rooftop window integrated flat roof structure of building. Solar Energy, 122: 834-846. https://doi.org/10.1016/j.solener.2015.10.012

[8] Nyers, J., Kajtar, L., Tomić, S., Nyers, A. (2015). Investment-savings method for energy-economic optimization of external wall thermal insulation thickness. Energy and Buildings, 86: 268-274. https://doi.org/10.1016/j.enbuild.2014.10.023

[9] Marshall, E., Steinberger, J.K., Dupont, V., Foxon, T.J. (2016). Combining energy efficiency measure approaches and occupancy patterns in building modelling in the UK residential context. Energy and Buildings, 111: 98-108. https://doi.org/10.1016/j.enbuild.2015.11.039

[10] Irshad, K., Habib, K., Saidur, R., Kareem, M.W., Saha, B.B. (2019). Study of thermoelectric and photovoltaic facade system for energy efficient building development: A review. Journal of Cleaner Production, 209: 13761395. https://doi.org/10.1016/j.jclepro.2018.09.245

[11] Wang, Q., Ploskić, A., Holmberg, S. (2015). Retrofitting with low-temperature heating to achieve energy-demand savings and thermal comfort. Energy and Buildings, 109: 217-229. https://doi.org/10.1016/j.enbuild.2015.09.047

[12] Noailly, J. (2012). Improving the energy efficiency of buildings: The impact of environmental policy on technological innovation. Energy Economics, 34(3): 795-806. https://doi.org/10.1016/j.eneco.2011.07.015

[13] Togashi, E., Miyata, M. (2019). Development of building thermal environment emulator to evaluate the performance of the HVAC system operation. Journal of Building Performance Simulation, 12(5): 663-684. https://doi.org/10.1080/19401493.2019.1601259

[14] Natephra, W., Motamedi, A., Yabuki, N., Fukuda, T. (2017). Integrating 4D thermal information with BIM for building envelope thermal performance analysis and thermal comfort evaluation in naturally ventilated environments. Building and Environment, 124: 194-208. https://doi.org/10.1016/j.buildenv.2017.08.004

[15] Reddy, K.S., Mudgal, V., Mallick, T.K. (2017). Thermal performance analysis of multi-phase change material layer-integrated building roofs for energy efficiency in built-environment. Energies, 10(9): 1367. https://doi.org/10.3390/en10091367

[16] Gowreesunker, B.L., Tassou, S.A. (2013). Effectiveness of CFD simulation for the performance prediction of phase change building boards in the thermal environment control of indoor spaces. Building and Environment, 59: 612-625. https://doi.org/10.1016/j.buildenv.2012.10.004

[17] Simpson, A., Fitton, R., Rattigan, I.G., Marshall, A., Parr, G., Swan, W. (2019). Thermal performance of thermal paint and surface coatings in buildings in heating dominated climates. Energy and Buildings, 197: 196-213. https://doi.org/10.1016/j.enbuild.2019.04.027

[18] Lee, S., Karava, P., Tzempelikos, A., Bilionis, I. (2019). Inference of thermal preference profiles for personalized thermal environments with actual building occupants. Building and Environment, 148: 714-729. https://doi.org/10.1016/j.buildenv.2018.10.027

[19] Li, B., Du, C., Yao, R., Yu, W., Costanzo, V. (2018). Indoor thermal environments in Chinese residential buildings responding to the diversity of climates. Applied Thermal Engineering, 129: 693-708. https://doi.org/10.1016/j.applthermaleng.2017.10.072

[20] Michels, C., Güths, S., Marinoski, D.L., Lamberts, R. (2018). Development of an experimental test rig for the evaluation of the thermal performance of building roofs. Energy and Buildings, 180: 32-41. https://doi.org/10.1016/j.enbuild.2018.09.023

[21] Woo Moon, J., Lee, J.H., Kim, S. (2016). Influence of control logic on variation of indoor thermal environment for residential buildings. Indoor and Built Environment, 25(6): 916-933. https://doi.org/10.1177/1420326X15588769 